\title{
Iodine content of salt 2 years after the introduction of the universal salt iodisation legislation in Lesotho
}

\author{
Masekonyela Linono Damane Sebotsa ${ }^{1,2 *}$, Andre Dannhauser ${ }^{2}$, Pieter L. Jooste ${ }^{3}$ and Gina Joubert ${ }^{4}$ \\ ${ }^{1}$ P/Bag A78, Maseru 100, Lesotho \\ ${ }^{2}$ Department of Human Nutrition, University of the Free State, South Africa \\ ${ }^{3}$ Nutritional Intervention Research Unit of the Medical Research Council, South Africa \\ ${ }^{4}$ Department of Biostatistics, University of the Free State, South Africa
}

(Received 24 February 2004 - Revised 6 September 2004 - Accepted 27 September 2004)

\begin{abstract}
The aim of the present study was to assess the impact of the universal salt iodisation legislation on I levels of salt at household, retail and entry level in Lesotho. We used a multistage proportion to population size method to select thirty-one clusters from all the districts and ecological zones of Lesotho. In each cluster, thirty households were randomly selected and salt samples were collected. Six salt samples from two randomly selected retailers in each cluster, and a total of 107 salt samples from all the commercial entry points in the country were also collected. Lesotho does not produce salt and it imports almost all its salt from South Africa. The salt samples were analysed using the iodometric titration method. The median I concentration of salt was $36.2 \mathrm{ppm}$ at entry point, $37.3 \mathrm{ppm}$ at retail level and $38.5 \mathrm{ppm}$ at household level. At household level only $1.6 \%$ used non-iodised salt and $86.9 \%$ used adequately iodised salt. Of all salt collected at household level, $20.4 \%$ was coarse salt, which was significantly less well iodised than fine salt. The study demonstrates a major achievement in the availability of iodised salt as well as household use of adequately iodised salt. Under-iodisation of coarse salt and non-uniformity of salt iodisation at the production site were observed. Therefore, there is a need for enforcement of the salt iodisation legislation especially at entry-point level to ensure that only iodised salt enters the country. During enforcement more emphasis should be given to iodisation of coarse salt.
\end{abstract}

Salt iodisation; Household level; Retail level; Entry-point level; Universal salt iodisation legislation

The most cost-effective and sustainable intervention to eliminate I deficiency disorders (IDD) is the iodisation of all edible salt (Mannar \& Dunn, 1995). The effectiveness of iodised salt prophylaxis, to correct I deficiency and reduce goitre prevalence has been reported in several international studies (World Health Organization, UNICEF and International Committee on Control of Iodine Deficienecy Disorders, 1996). It has also been stated that if iodised salt containing the required concentration of $\mathrm{I}$ is widely available and consumed in a community, there will, in a year's time, be no further birth of cretins or children with subnormal mental and physical development that can be attributed to I deficiency (Mannar \& Dunn, 1995). Mannar \& Dunn (1995) also state that children will be active and perform better in school and further enlargement of thyroid in adults will be prevented. Recognising this unique opportunity, there has been international commitment to ensure universal iodisation of all salt for human and animal consumption by 1995 (World Health Organization, UNICEF and International Committee on Control of Iodine Deficienecy Disorders, 1996).

Studies conducted in Lesotho since 1960 have reported mild to severe IDD. An IDD control programme was initiated in 1991 by the Micronutrient Task Force (multisectoral body dealing with micronutrient activities in the country) to eliminate IDD in the country (Ministry of Health, 1991). Two interventions were identified as the major components of the IDD control programme: salt iodisation as a long-term intervention; iodised oil capsule supplementation as a short-term intervention.

The legislation on universal salt iodisation was drafted in 1994. It states that food-grade salt or other salt intended for both human and animal consumption, which is exported to Lesotho, must be iodised with $\mathrm{KIO}_{3}$ and contain not less than $40 \mathrm{ppm}$ and not more than $60 \mathrm{ppm}$ of I on entering the country. Exemptions from these regulations include salt intended for use in the manufacture of compound foodstuffs and salt used for experimental purposes. This legislation was made law in 1999 and promulgated in March 2000. Lesotho does not produce salt and almost all of the salt entering the country comes from South Africa, where legislation does not include mandatory iodisation of salt meant for animal consumption. The salt meant for animal consumption in Lesotho is coarse salt packed in $20 \mathrm{~kg}$ bags or more. The legislation in Lesotho allows customs officials to do random-check tests at all ports of entry and health inspectors at retail and wholesale level. A person who contravenes the regulation is liable on conviction to a fine not exceeding 1000 Maloti or imprisonment for a period not exceeding 1 year. In addition to a fine or imprisonment, the health inspectors shall confiscate such salt. Studies 
in Lesotho have, however, shown an increase in the use of iodised salt despite the fact that there is no universal salt iodisation in South Africa (Sebotsa et al. 2002, 2003). These impressive results on the increased use of iodised salt in Lesotho were due to the spillover effect of mandatory salt iodisation in South Africa. Communities were made aware of IDD and the importance of using salt labelled 'iodised salt'. The awareness campaigns were done through community gatherings, media, local newspapers, posters and pamphlets. The IDD Control Task Force was formed to ensure enforcement of the legislation in 2000. However, due to logistical problems facing the Task Force, such as lack of funds, lack of commitment, transfer of some members within and between ministries, enforcement of the legislation was done only in 2000-1. There has been no monitoring and evaluation of salt I levels since the promulgation of the universal salt iodisation legislation in the country. Therefore, the aim of the present study was to evaluate the salt iodisation levels 2 years after the introduction of the legislation on universal salt iodisation.

\section{Materials and methods}

\section{Sampling}

The multistage proportionate to population size cluster sampling method was applied based on World Health Organization, UNICEF and International Committee on Control of Iodine Deficienecy Disorders (2001) recommendations. A total of thirty-one clusters (villages) were proportionally selected from the ecological zones in all ten districts of Lesotho (Fig. 1) based on the total number of households in each district and ecological zone.

\section{Data collection at household level}

In each of the thirty-one selected clusters, thirty households were selected to give salt samples. The centre of the village was identified and the direction of the top of the bottle that had been spun was taken. The number of the houses in the line of the direction was counted from the centre to the edge and one house was chosen at random as the starting point. The houses were given numbers, which were picked up from a tin. The household with a picked number was selected as the starting point. A total of 930 (thirty households $\times$ thirty-one clusters) salt samples were collected at household level.

\section{Data collection at retail level}

Two retailers in each cluster were also randomly selected and six salt samples purchased. The village chief was asked to name all the retailers in the cluster and the pieces of paper with names on them were put in a tin, mixed and two pieces drawn at random. Three $500 \mathrm{~g}$ or alternatively $1 \mathrm{~kg}$ packets of salt samples (preferably different brands available) were purchased by the field workers from the first retailer and three samples from the second retailer, resulting in a total of six salt samples in each cluster. In the case of salt packed in $20 \mathrm{~kg}$ bags, half a cup of salt was obtained and put into a plastic bag, which was then tightly sealed. Labelled stickers were used to identify the samples. A total of 186 (six salt samples $\times$ thirty-one clusters) were collected at retail level.

\section{Data collection at entry-point level}

There are thirteen entry points (or border posts) in the country, of which six are commercial (goods are allowed to pass) and seven are non-commercial (goods are not allowed to pass). Salt samples were purchased by the field workers at all the commercial entry points; $500 \mathrm{~g}$ or alternatively $1 \mathrm{~kg}$ packets of different brands of salt were randomly obtained from each wholesaler or retailer at all the commercial entry points of Lesotho. Two salt samples (preferably different brands) were purchased from the first vehicle at the entry point then two from the next one until enough samples were collected. In the case of salt packed in $20 \mathrm{~kg}$ bags, the bag was opened and half a cup of salt taken and put in a plastic bag, which was then tightly sealed. Labelled stickers were used for identification. A total of 110 salt samples were collected at entry points.

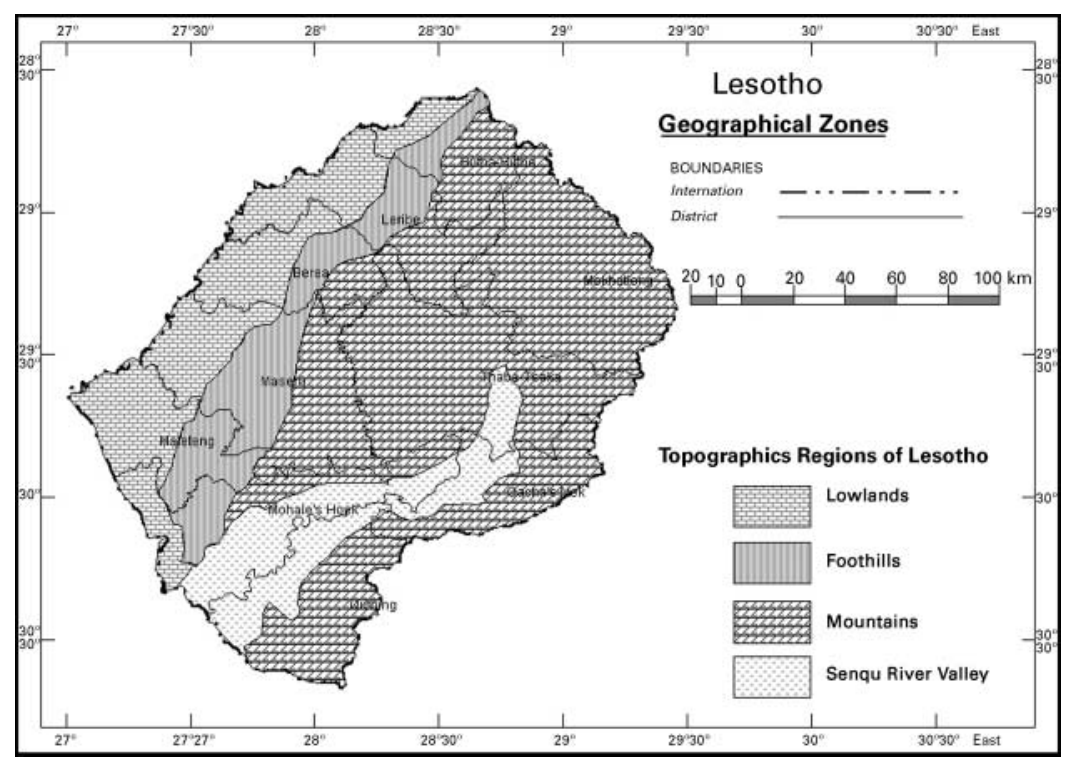

Fig. 1. Ecological zones of Lesotho. 


\section{Iodine analysis in salt}

The iodometric titration method was selected for chemical analysis of salt samples at the Medical Research Council (Cape Town) following the method of Mannar \& Dunn (1995) and Program Against Micronutrient Malnutrition, Micronutrient Initiative and International Committee on Control of Iodine Deficiency Disorders (1995). The cv for the analysis of I in salt by the iodometric titration method in this laboratory was 2.7 at a concentration of $50 \mathrm{ppm}$. With standard solutions of $\mathrm{KIO}_{3}$ at concentrations of 25 and $70 \mathrm{ppm}$, the $\mathrm{CV}$ was $1 \cdot 0$. The operation sensitivity, that is, the lowest concentration detectable in standard solutions, was $1 \mathrm{ppm}$ and the $\mathrm{CV}$ was 6.5 at this level.

\section{Statistical analysis}

Statistical analysis was performed by the Department of Biostatistics at the University of the Free State using the SAS software (SAS Institute Inc., 1989). The results were summarised by frequencies and percentages (categorical variables) and by means and ranges or medians in the case of skew distributions (numerical variables). Subgroup comparisons were done using the Kruskal-Wallis test for numerical variables and $\chi$ squared tests for categorical variables; $95 \%$ CI, taking the design effect of the cluster design into account, was calculated for the main categorical outcomes.

\section{Ethics}

The Ethics Committee of the Faculty of Health Sciences at the University of Free State gave its approval for conducting this study (ethics document no. ETOVS NR 32/02). Written approval was also obtained from the Ministry of Local government and Customs in Lesotho and from the chiefs of the selected villages.

\section{Results}

A total of 930 and 186 salt samples were successfully collected at household and retail level, respectively, and analysed. At entrypoint level 107 salt samples were collected and analysed instead of the expected 110 samples due to time constraints.

\section{Entry-point level}

The median I concentration of salt at entry point level was $36.2 \mathrm{ppm}$, which ranged from $30.5 \mathrm{ppm}$ (Monontsa) to $55.4 \mathrm{ppm}$ (Sani-top) in the different entry points (Table 1) $(P=0 \cdot 024)$. There was a large variation in the I concentration of salt within $(0-149 \mathrm{ppm}$ in Maseru) and between (12.0-50.6 ppm in Monontsa and $0-149 \mathrm{ppm}$ in Maseru) the border gates.

According to Table 2, the median I content of different brands at entry-point level ranged from 12.1 to $44.4 \mathrm{ppm}(P=0.050)$. A large variation was also observed in the I content of salt within the brands (where the largest variation was $4.9-143.3 \mathrm{ppm}$ and between the brands (1.9-35.9 and 4.9-143.3 ppm). Except for some samples of coarse salt, all the salt samples were labelled 'iodised salt'.

Table 3 shows that only $25 \cdot 2 \%$ of salt at entry-point level complied with the legal requirements of $40-60 \mathrm{ppm}$ of $\mathrm{I}$ in salt when entering the country. Few samples $(11.2 \%)$ exceeded the legal limit and their I content reached up to $149 \mathrm{ppm}$. More than half of the salt samples $(37 \cdot 4+26 \cdot 2=63.6 \%)$ were below the legal limit, of which $26.2 \%$ were markedly under-iodised or not iodised at all.

\section{Retail level}

The median I concentration at retail level was $37.3 \mathrm{ppm}$ (Table 4), which ranged from $12.4 \mathrm{ppm}$ in the Buthabuthe district to

Table 1. The iodine concentration of salt at entry-point level

\begin{tabular}{|c|c|c|c|c|c|c|}
\hline \multirow[b]{2}{*}{ Entry points } & \multirow[b]{2}{*}{ Sample size } & \multicolumn{5}{|c|}{ I concentration (ppm) } \\
\hline & & Mean & Range & Median & 25th percentile & 75th percentile \\
\hline Qacha'snek & 10 & 28.5 & $3.9-45.4$ & 34.9 & $12 \cdot 9$ & $37 \cdot 3$ \\
\hline Sani-top (Mokhotlong) & 10 & $57 \cdot 6$ & $22 \cdot 2-119 \cdot 8$ & $55 \cdot 4$ & 41.5 & 69.9 \\
\hline Monontsa (Butha-Buthe) & 10 & $30 \cdot 1$ & $12 \cdot 0-50 \cdot 6$ & 30.5 & $15 \cdot 0$ & 44.5 \\
\hline Vanroyen (Mafeteng) & 10 & $41 \cdot 6$ & $16 \cdot 1-88 \cdot 2$ & $38 \cdot 3$ & $32 \cdot 6$ & $45 \cdot 3$ \\
\hline Maputsoe (Berea) & 20 & $44 \cdot 9$ & $8 \cdot 8-143 \cdot 3$ & $36 \cdot 2$ & $31 \cdot 2$ & $52 \cdot 1$ \\
\hline Maseru & 47 & $31 \cdot 1$ & $0-149 \cdot 0$ & 34.9 & $12 \cdot 1$ & $41 \cdot 8$ \\
\hline Total & 107 & $36 \cdot 8$ & $0-149 \cdot 0$ & $36 \cdot 2$ & $18 \cdot 2$ & $45 \cdot 4$ \\
\hline
\end{tabular}

For details of samples and procedures, see p. 918

Table 2. The iodine concentration of different salt brands at entry-point leve

\begin{tabular}{|c|c|c|c|c|c|c|}
\hline \multirow[b]{2}{*}{ Brands } & \multirow[b]{2}{*}{ Sample size } & \multicolumn{5}{|c|}{ I concentration (ppm) } \\
\hline & & Mean & Range & Median & 25th percentile & 75th percentile \\
\hline 1 & 23 & 41.5 & $2 \cdot 9-119 \cdot 8$ & $36 \cdot 2$ & $30 \cdot 9$ & $50 \cdot 6$ \\
\hline 2 & 32 & 33.0 & $0-88.2$ & $36 \cdot 7$ & $17 \cdot 9$ & $44 \cdot 6$ \\
\hline 3 & 7 & 41.9 & $16 \cdot 0-89 \cdot 5$ & $41 \cdot 6$ & $16 \cdot 1$ & $63 \cdot 0$ \\
\hline 4 & 11 & 33.5 & $8 \cdot 8-50 \cdot 5$ & $34 \cdot 3$ & 28.9 & 43.7 \\
\hline 5 & 9 & $19 \cdot 7$ & $1.9-35.9$ & $17 \cdot 2$ & $15 \cdot 0$ & 31.6 \\
\hline 6 & 9 & $47 \cdot 4$ & $15 \cdot 4-149 \cdot 0$ & 37.9 & $24 \cdot 3$ & $49 \cdot 4$ \\
\hline 7 & 7 & $22 \cdot 2$ & $0-47 \cdot 1$ & $12 \cdot 1$ & $5 \cdot 0$ & $45 \cdot 8$ \\
\hline 8 & 9 & $56 \cdot 3$ & $4 \cdot 9-143 \cdot 3$ & $44 \cdot 4$ & 37.9 & $55 \cdot 8$ \\
\hline
\end{tabular}

For details of samples and procedures, see p. 918. 
Table 3. The distribution of iodine concentration of salt at entry-point level

\begin{tabular}{lrr}
\hline & \multicolumn{2}{c}{ Salt samples } \\
\cline { 2 - 3 } I concentration & $n$ & $\%$ \\
\hline $0-19$ & 28 & $26 \cdot 2$ \\
$20-39$ & 40 & $37 \cdot 4$ \\
$40-60$ & 27 & $25 \cdot 2$ \\
$61-80$ & 6 & $5 \cdot 6$ \\
$>80$ & 6 & $5 \cdot 6$
\end{tabular}

For details of samples and procedures, see p. 918.

$50 \cdot 2 \mathrm{ppm}$ in the Thabatseka district $(P=0 \cdot 010)$. The I content of salt at retail level ranged from 0 to $423.6 \mathrm{ppm}$. Similar to the results obtained at entry-point level, there was a large variation of I content of salt within (1.7-423.6 ppm in Leribe) and between (5.6-40.8 ppm in Buthabuthe and $1 \cdot 7-423.6 \mathrm{ppm}$ in Leribe) the districts. Similar to the entry-point level, at retail level all salt samples were labelled 'iodised salt' except for some coarse salt samples.

The median I concentration of different brands of salt ranged from 3.9 to $88.4 \mathrm{ppm}(P<0.001)$. The I content of brands varied considerably within (where the largest variation was $0-423.6 \mathrm{ppm})$ and between $(3.8-13.9$ and $0-423.6 \mathrm{ppm})$ the brands.

\section{Household level}

Nationally, the median I concentration at household level was $38.5 \mathrm{ppm}$, which ranged from $29.2 \mathrm{ppm}$ in the Thabatseka district to 43.2 ppm in the Quthing district $(P<0.001$; Table 5). A large variation was observed in the I content of salt within (where the largest variation was 9.6-591.0 ppm in Buthabuthe district) and between (0-76.4 ppm in Qachas'nek and 9.6-591.0 ppm in Buthabuthe district) the districts. Table 5 also shows that the median I concentration was higher $(40 \cdot 2 \mathrm{ppm})$ in the Lowlands and Senqu river valley $(40.0 \mathrm{ppm})$ and lower $(33.1 \mathrm{ppm})$ in the Mountains than in the other ecological zones $(P<0 \cdot 001)$. There was a large variation in the I content of salt within $(0-686.5 \mathrm{ppm}$ in the Lowlands) and between $(0-257.5 \mathrm{ppm}$ in the Mountains and $0-686.5 \mathrm{ppm}$ in the Lowlands) the different ecological zones.

Table 6 indicates that the mean I concentration of coarse salt $(33.5 \mathrm{ppm})$ was lower than that of fine salt $(48.3 \mathrm{ppm})$ $(P<0.001)$. There was a larger variation in the I content of coarse salt $(0-686.5 \mathrm{ppm})$ than that of fine salt $(0-591 \mathrm{ppm})$.

Nationally, only $1.6 \%$ of households used non-iodised salt and $98.4 \%$ of households $(86.9+11.5)$ used iodised salt (Table 7). Of the salt samples that were non-iodised, more $(5.8 \%)$ were coarse salt than fine salt $(0.5 \%)$. The majority of households $(86.9 \%)$ (95\% CI 83.1, 90.7) used adequately iodised salt (>15 ppm). More of the fine salt samples $(93.7 \%)$ than of the coarse salt samples $(60.5 \%)$ were adequately iodised.

\section{Discussion}

The median I concentration of salt at the point of entry of $36 \cdot 2 \mathrm{ppm}$ is lower than the legal limit of $40-60 \mathrm{ppm}$ specified in the universal salt iodisation legislation for Lesotho. Only $25.2 \%$ complied with the legal requirements. Lesotho does not produce salt and almost all of the salt entering the country

Table 4. The iodine concentration of salt at retail level

\begin{tabular}{|c|c|c|c|c|c|c|}
\hline \multirow[b]{2}{*}{ District } & \multirow[b]{2}{*}{ Sample size } & \multicolumn{5}{|c|}{ I concentration (ppm) } \\
\hline & & Mean & Range & Median & 25th percentile & 75th percentile \\
\hline Mokhotlong & 6 & $20 \cdot 8$ & $5 \cdot 8-38 \cdot 5$ & $18 \cdot 4$ & $10 \cdot 6$ & $33 \cdot 2$ \\
\hline Buthabuthe & 6 & $19 \cdot 8$ & $5 \cdot 6-40 \cdot 8$ & $12 \cdot 4$ & $7 \cdot 2$ & $40 \cdot 6$ \\
\hline Leribe & 30 & $108 \cdot 6$ & $1 \cdot 7-423 \cdot 6$ & $42 \cdot 6$ & $15 \cdot 7$ & $128 \cdot 8$ \\
\hline Berea & 18 & $35 \cdot 6$ & $0-91 \cdot 3$ & $34 \cdot 3$ & $17 \cdot 7$ & $50 \cdot 1$ \\
\hline Maseru & 54 & $37 \cdot 4$ & $3 \cdot 9-83.5$ & $39 \cdot 8$ & $27 \cdot 9$ & $49 \cdot 1$ \\
\hline Mafeteng & 24 & $35 \cdot 4$ & $7 \cdot 5-58 \cdot 3$ & $35 \cdot 1$ & $24 \cdot 6$ & $48 \cdot 7$ \\
\hline Mohaleshoek & 18 & 34.9 & $19 \cdot 6-51 \cdot 9$ & $35 \cdot 2$ & $28 \cdot 0$ & $41 \cdot 2$ \\
\hline Quthing & 12 & $72 \cdot 0$ & $19 \cdot 7-254 \cdot 8$ & $49 \cdot 0$ & $36 \cdot 7$ & $64 \cdot 2$ \\
\hline Qachas'nek & 6 & $31 \cdot 3$ & $16 \cdot 5-50 \cdot 7$ & $30 \cdot 4$ & $27 \cdot 3$ & $32 \cdot 7$ \\
\hline Thabatseka & 12 & $52 \cdot 3$ & $13 \cdot 9-106 \cdot 8$ & $50 \cdot 2$ & $33 \cdot 3$ & $58 \cdot 4$ \\
\hline Total & 186 & $50 \cdot 1$ & $0-423 \cdot 6$ & $37 \cdot 3$ & $23 \cdot 0$ & $50 \cdot 7$ \\
\hline
\end{tabular}

For details of samples and procedures, see p. 918.

Table 5. The iodine concentration of salt at household level by ecological zones

\begin{tabular}{|c|c|c|c|c|c|c|}
\hline \multirow[b]{2}{*}{ Ecological zones } & \multirow[b]{2}{*}{ Sample size } & \multicolumn{5}{|c|}{ I concentration (ppm) } \\
\hline & & Mean & Range & Median & 25th percentile & 75th percentile \\
\hline Foothills & 150 & $47 \cdot 1$ & $0-591 \cdot 0$ & $39 \cdot 2$ & $23 \cdot 0$ & $52 \cdot 2$ \\
\hline Lowlands & 540 & $60 \cdot 3$ & $0-686.5$ & $40 \cdot 2$ & $27 \cdot 7$ & $50 \cdot 9$ \\
\hline Senqu-river valley & 30 & $47 \cdot 2$ & $0-423 \cdot 2$ & $40 \cdot 0$ & $29 \cdot 3$ & $52 \cdot 2$ \\
\hline Mountains & 210 & $36 \cdot 8$ & $0-257 \cdot 5$ & $33 \cdot 1$ & $18 \cdot 1$ & $45 \cdot 5$ \\
\hline Total & 930 & $45 \cdot 3$ & $0-686 \cdot 5$ & $38 \cdot 5$ & $25 \cdot 8$ & $50 \cdot 4$ \\
\hline
\end{tabular}

For details of samples and procedures, see p. 918. 
Table 6. The iodine concentration of different types of salt at household level

\begin{tabular}{lcccccc}
\hline & & \multicolumn{4}{c}{ I concentration (ppm) } \\
\cline { 3 - 7 } Type of salt & Sample size & Mean & Range & Median & 25th percentile & 75th percentile \\
\hline Coarse & 190 & 33.5 & $0-686.5$ & 18.5 & $10 \cdot 4$ & $38 \cdot 1$ \\
Fine & 740 & 48.3 & $0-591.0$ & 40.9 & 30.8 & $52 \cdot 1$ \\
\hline
\end{tabular}

For details of samples and procedures, see p. 918.

Table 7. The use of adequately iodised salt at household level

\begin{tabular}{|c|c|c|c|c|c|c|}
\hline \multirow[b]{3}{*}{ Type of salt } & \multicolumn{6}{|c|}{ Number of salt samples in each category of salt iodisation } \\
\hline & \multicolumn{2}{|c|}{$0 \mathrm{ppm}$} & \multicolumn{2}{|c|}{$\leq 15 \mathrm{ppm}$} & \multicolumn{2}{|r|}{$>15 \mathrm{ppm}$} \\
\hline & $n$ & $\%$ & $n$ & $\%$ & $n$ & $\%$ \\
\hline Coarse & 11 & $5 \cdot 8$ & 64 & 33.7 & 115 & $60 \cdot 5$ \\
\hline Fine & 4 & 0.5 & 43 & $5 \cdot 8$ & 693 & 93.7 \\
\hline Total & 15 & 1.6 & 107 & 11.5 & 808 & $86.9(95 \% \mathrm{Cl} 83.1,90 \cdot 7)$ \\
\hline
\end{tabular}

comes from South Africa, where it is obtained from production sites and wholesalers. A minimal loss of I is therefore expected to occur from producers and wholesalers in South Africa to entry points in Lesotho. This is based on the fact that a study in India showed that small I losses of 9-10\% occurred within $15-20 \mathrm{~d}$ after packaging in polythene bags, whereafter the I content remained constant for $300 \mathrm{~d}$ (Chauhan et al. 1992). Many studies have also shown that $\mathrm{KIO}_{3}$, which is used to iodise salt in South Africa, is more stable than $\mathrm{KI}^{-}$.

At retail level, the median I concentration of $37.3 \mathrm{ppm}$ was approximately the same as that obtained at entry-point level. There was a range of $7.2-152.8 \mathrm{ppm}$ among the brands, which is very wide. A recent study in Lesotho also indicated a variation of 9-76 ppm among the brands and 12-76 ppm within the brands at retail level (Sebotsa et al. 2002). This wide variation is expected at household level, where there are different storage conditions. At retail level and entry-point level, the large variation implies non-uniformity in salt iodisation. Mannar \& Dunn (1995) have indicated that during salt iodisation, thorough mixing of the salt after the addition of $\mathrm{KIO}_{3}$ is necessary to ensure even penetration of $\mathrm{KIO}_{3}$. However, when there is variability in the amount of premix or spray added, some batches of salt will contain too much I and others too little.

The median I concentration in household salt of $38.5 \mathrm{ppm}$ was approximately the same as that obtained at retail level and entrypoint level. These findings suggest that I has not been lost significantly during transportation but there is under-iodisation of salt by the producers. Similar results confirming under-iodisation at the production site were obtained in South Africa, where the mean I concentration of fine and coarse salt was $30 \mathrm{ppm}$, which ranged from 1 to $55 \mathrm{ppm}$ and only $25.6 \%$ of producer's salt complied with the legal requirement of 40-60 ppm of I (Jooste, 2003). A large variation in the I concentration of salt $(0-686.5 \mathrm{ppm})$ at household level was observed. Similarly, a quantitative study conducted in the country in 1998 indicated a variation in I levels among brands ranging from 0 to $97 \mathrm{ppm}$ and within brands ranging from 7 to $97 \mathrm{ppm}$ at household level (Sebotsa et al. 2002). Other similar international studies have also shown large variations in I levels of salt (Muture \& Wainana 1994; Jooste et al. 1998).
The median I concentration in the Lowlands was higher than that in the Mountains. The geographical variation in I concentration has been observed in earlier studies conducted in Lesotho and appears to be a worldwide problem. In Lesotho most households in the Mountains use non-iodised salt (Sebotsa et al. 2002, 2003). This situation in the country is mainly due to the fact that most households that rear animals are in the Mountains, with few in the Lowlands (Gay \& Hall, 2001). Coarse salt is therefore purchased for animal consumption but is apparently used for human consumption as well. This is the main reason why legislation in Lesotho includes iodisation of salt for animal consumption.

According to legislation in South Africa, iodisation of salt meant for animal consumption, which is coarse salt packed in bags of $20 \mathrm{~kg}$ or more, is not compulsory. Only coarse salt packed in $500 \mathrm{~g}$ or $1 \mathrm{~kg}$ bags meant for human consumption is iodised. Impressively, the present study indicated an I content of coarse salt ranging from 1.7 to $254.8 \mathrm{ppm}$ and that only $5.8 \%$ of coarse salt contained no I at household level. In addition, the study in South Africa indicated median I content of $38 \mathrm{ppm}$ in both fine and coarse salt at the production site, indicating that coarse salt could be as effectively iodised as fine salt (Jooste, 2003). The median I concentration of coarse salt was, however, less than that of fine salt in the present study. Also, a higher percentage of fine salt $(93.7 \%)$ and a lower percentage of coarse salt $(60.5 \%)$ was adequately iodised, and $5.8 \%$ of coarse salt and only $0.5 \%$ of fine salt was non-iodised at household level. The possible reason for the variations in I content of the two types of salt is that fine salt seems to retain I longer than coarse salt, probably because of the uniform crystal size of fine salt and its free-running property (Ranganathan \& Rao, 1986) and the impermeable bags used for packaging fine salt (Mannar \& Dunn, 1995). Another possible reason may be higher levels of impurities in coarse salt than in fine salt.

More than $90 \%$ (98.4\%) of households used iodised salt with only $1.6 \%$ using non-iodised salt, compared with $15.3 \%$ of the households in 1998 (Sebotsa et al. 2002) and 5.2\% in 1999. These findings show that Lesotho has managed to achieve almost universal household use of iodised salt despite the fact that there has been no monitoring of salt I levels and enforcement of the legislation since it was enacted. The impressive results on 
the increase in the use of iodised salt in Lesotho implies that Lesotho benefits from mandatory salt iodisation, which was introduced in South Africa in 1995. A major achievement has also been observed in the coverage of household use of adequately iodised salt of $86.9 \%$ compared with $81.8 \%$ in 1999 (Sebotsa et al. 2002). These results show an excellent progress in attaining I nutrition in Lesotho. Under-iodisation or inconsistent iodisation of coarse salt is a major factor contributing to a slightly lower coverage of household use of iodised salt.

The daily per capita salt intake of $3-10 \mathrm{~g} / \mathrm{d}$ (Bureau of Statistics, 2001) is equivalent to a mean daily I intake of $135 \cdot 9-453 \mu \mathrm{g}$. This mean I intake appears to be safe when considering the expected I losses of $20 \%$ during the preparation of food (World Health Organization, 1996). It has been reported that high levels of I intake, particularly during the introduction of a salt iodisation programme, increase the risk of adverse effects where the most serious complication observed in areas of endemic goitre during salt iodisation is a transient increase in I-induced hyperthyroidism (Todd et al. 1995; Stanbury et al. 1998). However, the benefits of correcting I deficiency through salt iodisation far outweigh the risk of I-induced hyperthyroidism (Baltisberger et al. 1995; Delange, 1998).

\section{Conclusion}

The results of the present study indicate that there is a great improvement in the household use of iodised salt and adequately iodised salt despite lack of monitoring of I levels and enforcement of the legislation. A wide variation between and within the different brands, implying non-uniformity in salt iodisation at production sites, was also demonstrated. Coarse salt was less iodised than fine salt and has contributed to the use of salt that is not adequately iodised at household level. The level of salt iodisation was also lower in the Mountains than in the Lowlands, and this is possibly due to the more intensive use of non-iodised salt in the Mountains than in the Lowlands. There is therefore a need for improvement in consistent levels of I in salt, variation in salt I levels and iodisation of coarse salt. The findings of the present study suggest that in countries such Lesotho which do not produce salt, the introduction of the salt iodisation legislation should be followed with a well and carefully controlled enforcement programme.

A large variation in the I content of salt and non- or under-iodisation of coarse salt observed in the study needs to be given special attention. The IDD control task force should visit all South Africa producers supplying salt to Lesotho. The salt producers should be made aware of the very important role they play in eliminating IDD in South Africa and all the countries to which salt is exported. During the visits there should be emphasis on consistency in amounts of premix or spray addition as well as iodisation of coarse salt. Of particular importance is the initiation of an effective enforcement programme in Lesotho, which needs a strong political will to be sustainable.

\section{Acknowledgements}

This study was financially supported by the Food and Nutrition Coordinating Office in Lesotho. We would like to thank Emmerentia Strydom of the Medical Research Council for chemical analysis. We are also grateful to data collectors, the participating households, retailers, wholesalers and customs officials.

\section{References}

Baltisberger BL, Minder CE \& Burgi H (1995) Decrease of incidence of toxic modular goitre in a region of Switzerland after full correction of mild I deficiency. European Journal of Endocrinology 132, 546-549.

Bureau of Statistics (2001) Report on Foreign Trade and Statistics. Maseru Lesotho: Ministry of Economic Planning.

Chauhan SA, Bhatt AM \& Mayethia KM (1992) Stability of iodised salt with respect to I content. Research and Industry 37, 38-41.

Delange F (1998) Risks and benefits of I supplementation. The Lancet 351, 923-924.

Gay J \& Hall D (2001) Livelihoods in Lesotho. Maseru Lesotho: CARE. Jooste PL (2003) Assessment of the I concentration in table salt at the production stage in South Africa. Bulletin of the World Health Organization 81, 517-521.

Jooste PL, Weight MJ, Locatelli-Rossi L \& Lombard CJ (1998) Impact after one year of compulsory iodisation on the I content of table salt at retailer level in South Africa. International Journal of Food Science and Nutrition 50, 7-12.

Mannar VMG \& Dunn JT (1995) Salt Iodisation for the Elimination of Iodine Deficiency. Netherlands: International Committee on Control of Iodine Deficiency Disorders.

Ministry of Health (1991) Proposal for a National Program on the Prevention and Control of IDD in Lesotho. Maseru Lesotho: Nutrition Department of Family Health Division.

Muture BN \& Wainana JN (1994) Salt iodisation in Kenya for national prophylaxis of I deficiency disorders. African Medical Journal 71, 611-613.

Program Against Micronutrient Malnutrition, Micronutrient Initiative and International Committee on Control of Iodine Deficiency Disorders (1995) Monitoring Universal Salt Iodisation Programmes [KM Sullivan, R Houston, J Gorstein and J Cervinskas, editors]. Atlanta, GA: PAMM/MI/ICCIDD.

Ranganathan S \& Rao BSN (1986) Stability of I in iodised salt. Indian Food Industry 5, 122-124.

SAS Institute Inc. (1989) SAS Procedures Guide, 3rd ed., version 6. Cary, NC: SAS Institute Inc.

Sebotsa MLD, Dannhauser A, Jooste PL \& Joubert G (2003) Prevalence of goitre and urinary I status of primary school children in Lesotho. Bulletin of the World Health Organization 81, 28-34.

Sebotsa MLD, Huskissons J \& Jooste P (2002) The evaluation of the I content of table salt in Lesotho. African Journal of Health Sciences 9, $128-134$.

Stanbury JB, Ermans AE, Boudoux P, Todd C, Oken E, Tonglet R, Vidor G, Bravernan LE \& Mediros-netro G (1998) Iodine induced hyperthyroidsm: occurrence \& epidemiology. Thyroid 8, 83-100.

Todd CH, Allain T, Gomo Z, Hasler J, Ndiweni M \& Oken E (1995) Increase in thyrotoxicosis associated with I supplements in Zimbabwe. Lancet 346, 1563-1564.

World Health Organization (1996) Safe use of iodised oil to prevent I deficiency in pregnant women deficiency in pregnant women. Update. Bulletin of the World Health Organisations 74, 1-3.

World Health Organization, United Nations International Childrens' Emergency Fund and International Committee on Control of Iodine Deficiency Disorders (1996) Review of Findings from 7 Country Study in Africa on Levels of Salt Iodisation in Relation to Iodine Deficiency Disorders, Including Iodine Induced Hyperthyroidism, WHO/NUT/ 97.5. Geneva: WHO.

World Health Organization, United Nations International Childrens' Emergency Fund and International Committee on Control of Iodine Deficiency Disorders (2001) Indicators for Assessing Iodine Deficiency Disorders and their Control Through Salt Iodisation. Report of a joint WHO/UNICEF/ICCIDD Consultation. Geneva: WHO. 